\title{
Systematic review and meta-analysis of music interventions in hypertension treatment: a quest for answers
}

Anne Y. R. KühImann', Jonathan R. G. Etnel' ${ }^{2}$, Jolien W. Roos-Hesselink ${ }^{3}$, Johannes Jeekel ${ }^{4}$, Ad J. J. C. Bogers ${ }^{2}$ and Johanna J. M. Takkenberg ${ }^{2^{*}}$

\begin{abstract}
Background: Adverse effects, treatment resistance and high costs associated with pharmacological treatment of hypertension have led to growing interest in non-pharmacological complementary therapies such as music interventions. This meta-analysis aims to provide an overview of reported evidence on the efficacy of music interventions in the treatment of hypertension.

Methods: A systematic literature search was conducted for publications on the effect of music interventions on blood pressure in adult hypertensive subjects published between January 1990-June 2014. Randomized controlled trials with a follow-up duration $\geq 28$ days were included. Blood pressure measures were pooled using inverse variance weighting.

Results: Of the 1689 abstracts reviewed, 10 randomized controlled trials were included. Random-effects pooling of the music intervention groups showed a trend toward a decrease in mean systolic blood pressure (SBP) from $144 \mathrm{mmHg}(95 \% \mathrm{Cl}: 137-152)$ to $134 \mathrm{mmHg}(95 \% \mathrm{Cl}: 124-144)$, and in mean diastolic blood pressure (DBP) from $84 \mathrm{mmHg}(95 \% \mathrm{Cl}: 78-89)$ to $78 \mathrm{mmHg}(95 \% \mathrm{Cl}: 73-84)$. Fixed-effect analysis of a subgroup of 3 trials with valid control groups showed a significant decrease in pooled mean SBP and DBP in both intervention and control groups. A comparison between music intervention groups and control groups was not possible due to unavailable measures of dispersion.

Conclusions: This systematic review and meta-analysis revealed a trend towards a decrease in blood pressure in hypertensive patients who received music interventions, but failed to establish a cause-effect relationship between music interventions and blood pressure reduction. Considering the potential value of this safe, low-cost intervention, well-designed, high quality and sufficiently powered randomized studies assessing the efficacy of music interventions in the treatment of hypertension are warranted.
\end{abstract}

Keywords: Hypertension, Music intervention, Meta-analysis, Systemic review, Global health care delivery

\section{Background}

Hypertension has been documented as a major risk factor for cardiovascular morbidity and mortality $[1,2]$. Prevalence of hypertension in developed countries is estimated at $37 \%$ and is projected to increase to $42 \%$ by 2025 [3]. When life-style adjustment approaches fail in reducing blood pressure, the main treatment modality in

\footnotetext{
* Correspondence: j.j.m.takkenberg@erasmusmc.nl

${ }^{2}$ Department of Cardiothoracic Surgery, Erasmus University Medical Center,

P.O. Box 2040, 3000CA Rotterdam, The Netherlands

Full list of author information is available at the end of the article
}

hypertension is pharmacological treatment. Conventional pharmacological treatment is associated with high costs and various adverse effects particularly in cases of combination therapy and treatment resistant hypertension [4]. This has led to a growing interest in non-pharmacological complementary therapies, such as music interventions, in the treatment of hypertension.

Music interventions have been found to affect clinical outcomes in various situations, including short-term effects on blood pressure during medical procedures such as surgery to long-term effects in the treatment of sleep disorders 
or depression [5-8]. A recent meta-analysis of studies conducted in diverse clinical settings demonstrated that music interventions lead to a significant reduction in systolic blood pressure (SBP), diastolic blood pressure (DBP) and heart-rate in various disease states [9]. Another review found that listening to music may have a beneficial effect on anxiety, SBP, heart-rate, respiratory rate, quality of sleep and pain in patients with coronary heart disease [10].

Music interventions can be administered in different ways. They can be either live or recorded and administered either with or without the involvement of a music therapist. Moreover, the music intervention can be chosen by the patient, by a music therapist or by a healthcare practitioner - the latter especially in the case of research. There are various definitions of music-based interventions, such as 'music therapy', 'receptive music' and 'music medicine'. According to the definition of the American Music Therapy Association, music therapy is the clinical and evidence-based use of music interventions to accomplish individualized goals within a therapeutic relationship by a credentialed professional who has completed an approved music therapy program [11]. The therapeutic relationship is an important aspect in this definition. The term 'receptive music' is meant as a broader explanation of music-based interventions and encompasses several techniques in which the client is a recipient of the music experience [12]. It may also be part of a therapeutic relationship. Another definition is music medicine and can either refer to selected and often specially composed music which is thought to have an effect itself [13] or can be defined as passive listening to prerecorded music provided by medical personal other than a music therapist [14].

Several studies have been performed to examine the possible effects of music on hypertension. These studies are usually small in sample-size and an overview of reported outcomes is lacking. To investigate the potential antihypertensive effect of music interventions, we conducted a systematic review and meta-analysis of prospective randomized controlled trials that assessed the effect of music interventions on blood pressure in hypertensive patients.

In this article, we describe the effects of several types of music interventions in patients with hypertension. Overall, we will use the broader term music interventions. However when we specifically differentiate the interventions, we will refer to music therapy when a specific intervention includes the involvement of a music therapist in a therapeutic relationship. Music interventions without this therapeutic relationship will be referred to as recorded music interventions.

\section{Methods}

This systematic review was conducted according to the PRISMA guidelines [15]. The study was approved by the institutional review board (MEC 2014-384) and informed consent was waived. On June 6th, 2014 Embase, PubMed, Medline, Cochrane Central, Web of Science and Google Scholar were searched for publications on the effect of music on blood pressure in adult hypertensive patients (see Additional file 1). Results were screened manually on relevance by two independent investigators (AYRK, JRGE). Studies on the effect of music interventions on blood pressure in hypertensive patients with mean age $\geq 18$ years were considered for inclusion. Studies conducted in humans, published after 1/1/1990, written in English, German, French, Dutch, or Spanish and with a follow-up of at least 28 days were included. Studies were excluded if the full text was not available. Cohorts that received any additional treatment other than music and/or standard medical therapy were also excluded. Cohorts with a medical history of hypertension, with or without medical treatment, or a mean $\mathrm{SBP} \geq 140 \mathrm{mmHg}$ and/or $\mathrm{DBP} \geq 90 \mathrm{mmHg}$ at baseline were included [1]. Music interventions had to be administered multiple times during the trial period. There were no limitations on the type of music administered, nor on the timing of each intervention.

Methods of analysis and inclusion criteria were specified and documented in advance. Only the most recent or most complete study was included if there was an overlap in study populations. In case of disagreement on the inclusion of a paper, an agreement was negotiated.

\section{Data extraction \& statistical analyses}

Microsoft Office Excel 2011 (Microsoft Corp., Redmond, WA, USA) was used for data extraction and statistical analyses. The following patient and study characteristics were recorded: age, sex, systolic and diastolic blood pressure at baseline, history of hypertension, use of antihypertensive medication, comorbidities, details of music intervention and length of follow-up. Primary outcome measures were reduction in SBP and DBP and mean SBP and DBP at last follow-up. Secondary outcome measures were effects of music on anxiety and quality of life.

Weighted pooling was conducted on the patient characteristics. Mean SBP and DBP at baseline and at final follow up and mean reduction in SBP and DBP were pooled using inverse variance weighting in a randomeffects model. When the number of studies was not sufficiently large to reliably estimate the tau-squared statistic ( $<4$ studies), a fixed-effect model was used as well [16]. Studies that did not provide any measure of dispersion for the mean of a particular variable were excluded from the meta-analysis of that variable. Heterogeneity among the included studies was analyzed with both the Cochran Q statistic and the I2 index. Risk of bias among studies was assessed using the Cochrane Collaboration risk of bias assessment tool [17]. Funnel 
plots were used to investigate publication bias. Statistical significance was inferred at a $p$-value $<0.05$.

\section{Results}

The literature search resulted in 1689 publications. Ten of these studies, encompassing a total of 296 patients, met all of the described criteria and were included in the systematic review (Fig. 1) [2, 18-26]. All of these were randomized controlled trials published in English. Table 1 provides an overview of the included studies and baseline patient characteristics.

Nine studies evaluated the effects of recorded music interventions whereas one study evaluated the effects of music therapy [19]. There was a large variation in follow-up duration and in the type, timing and duration of music intervention sessions among the included studies. Seven of the 10 included studies compared music interventions to various other interventions and, thus, did not allow for comparative analysis. Mean age of the patients in the music intervention arms was $65.2 \pm 7.3$ years and $42 \%$ were male. A medical history of hypertension was reported in $92 \%$ of the patients and $78 \%$ used antihypertensive drugs.

Only three studies reported prevalence of comorbidities, such as respiratory disease or diabetes mellitus, which varied from 26 to $100 \%$ in their cohorts [18, 20, 23]. Overall, there was a moderate to high risk of bias among the included studies (see Additional file 2) [17]. Due to the small

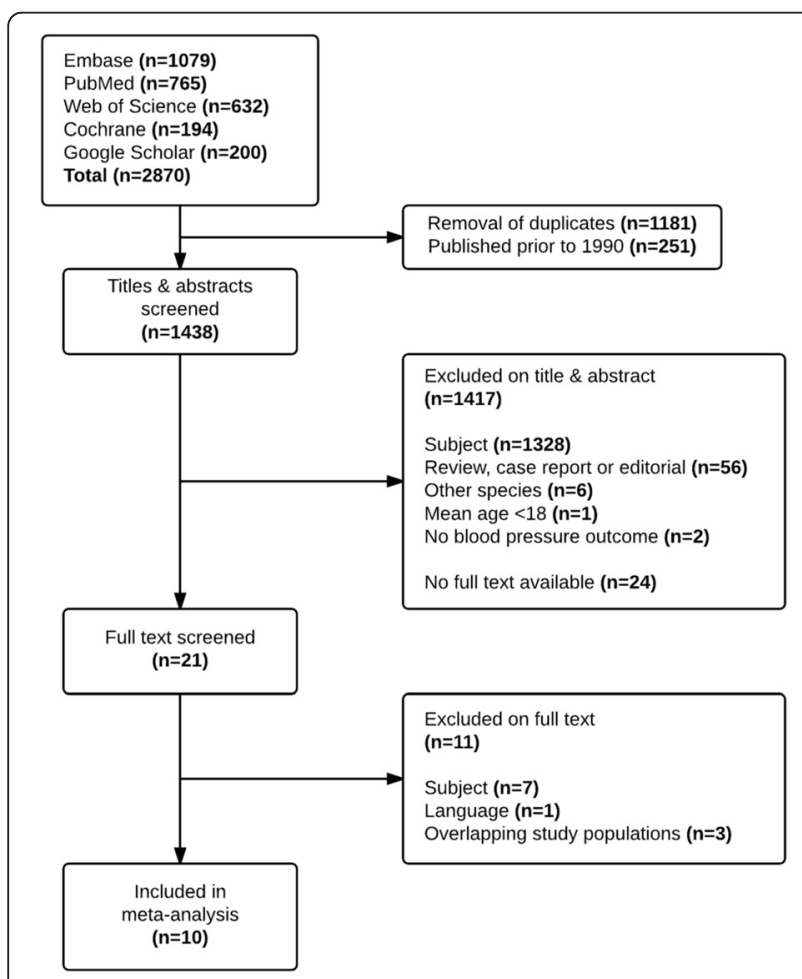

Fig. 1 Flowchart of literature search and study selection variation in sample size of the included studies, analysis of publication bias was inconclusive (see Additional file 3).

\section{Music interventions and blood pressure}

Table 2 shows blood pressure data of the music intervention arms of all ten included studies, pooled in a random-effects model. In the pooled analysis of mean SBP and DBP at baseline and last follow-up, music interventions were associated with a decrease in SBP from $144 \mathrm{mmHg}$ to $134 \mathrm{mmHg}$, as well as a decrease in DBP from $84 \mathrm{mmHg}$ to $78 \mathrm{mmHg}$. Pooling of the mean reduction in blood pressure in each study also showed a reduction in both systolic and diastolic blood pressure after music interventions, though due to unavailable measures of dispersion, five of the studies were excluded from this analysis. Strong evidence of heterogeneity was observed among all outcome measures.

\section{Music interventions versus standard care}

Three of the ten included studies compared music interventions to a control group that received either standard medical therapy or a resting period [18-20]. Mean age of the patients in the control groups was $73.6 \pm 7.8$ years and $53 \%$ were male. A medical history of hypertension was reported in $89 \%$ of the patients. When comparing pooled mean SBP/DBP at baseline with pooled mean SBP/DBP at the end of the trial period in a randomeffects model, a trend towards a decrease was found in pooled mean SBP and DBP in treatment as well as control groups, while fixed-effect analysis showed a significant decrease in both groups (Table 3). None of these 3 trials made a formal comparison of the observed reduction in blood pressure between the treatment and control groups. Although the magnitude of this reduction appeared to be greater in the experimental groups when represented graphically (Figs. 2 and 3), due to unavailable measures of dispersion a formal comparison of the mean reduction in SBP and DBP between the music interventions- and control group was not possible in this subgroup analysis.

\section{Anxiety and quality of life}

Five studies evaluated the effects of the music intervention on quality of life and anxiety $[2,18,19,23,24]$. One study found significant improvements in quality of life [19]. This finding was not supported by the other studies. Due to the large variety of questionnaires used in these studies, pooling of these results was not possible.

\section{Discussion}

This systematic review and meta-analysis of ten randomized controlled trials evaluating the effect of music interventions in the treatment of hypertension found a decrease in pooled mean SBP and DBP after application 
Table 1 Overview of publications, all RCTs

\begin{tabular}{|c|c|c|c|c|c|c|c|c|c|c|}
\hline First author & Year & Study arm & $N$ & Age (years) & $M \%$ & $\begin{array}{l}\text { History } \\
\text { of HT \% }\end{array}$ & $\begin{array}{l}\text { Anti-HT } \\
\text { drugs \% }\end{array}$ & $\begin{array}{l}\text { Follow-up } \\
\text { (days) }\end{array}$ & $\begin{array}{l}\text { Timing of } \\
\text { intervention }\end{array}$ & Description \\
\hline \multirow[t]{2}{*}{ Bekiroglu [18] $^{a}$} & 2013 & $M$ & 30 & $75.5(7.1)$ & 57 & 100 & 90 & 28 & $1 \times /$ day & Turkish Classical \\
\hline & & $C$ & 30 & $78.2(6.1)$ & 57 & 100 & 90 & & & Resting Period \\
\hline \multirow[t]{2}{*}{ Modesti [2] } & 2010 & M & 26 & $58.0(-)$ & 62 & 100 & 77 & 180 & $1 \times /$ day & Classical, Celtic, Indian \\
\hline & & C & 29 & $58.0(-)$ & 55 & 100 & 73 & & & $\begin{array}{l}\text { Music Guided Slow-Breathing } \\
\text { (Buteyko-Pranayama) }\end{array}$ \\
\hline \multirow[t]{2}{*}{ Zanini [19] ${ }^{\mathrm{a}}$} & 2009 & M & 23 & $66.5(9.1)$ & 30 & 100 & 100 & 84 & 1x/week & $\begin{array}{l}\text { Recreation, Improvisation, } \\
\text { Composition, Listening } \\
\text { of music }^{b}\end{array}$ \\
\hline & & C & 22 & $67.2(9.6)$ & 55 & 100 & 100 & & & $\begin{array}{l}\text { No Intervention (Standard } \\
\text { Medical Therapy) }\end{array}$ \\
\hline \multirow[t]{2}{*}{ Chan $[20]^{\mathrm{a}}$} & 2009 & M & 23 & $>60$ & 44 & 61 & - & 28 & 1x/day-1x/week & $\begin{array}{l}\text { Western-, Chinese-, Asian } \\
\text { Classical, Western Jazz }\end{array}$ \\
\hline & & C & 24 & $>60$ & 46 & 67 & - & & & Resting Period \\
\hline \multirow[t]{2}{*}{ Tang [25] } & 2009 & M & 22 & $85.0(5.0)$ & 18 & 59 & 32 & 84 & $3 \times /$ week & Mozart \\
\hline & & C & 19 & $86.0(6.0)$ & 11 & 68 & 42 & & & $\begin{array}{l}\text { Audio Relaxation Program } \\
\text { Training (Revitalizer II) }\end{array}$ \\
\hline \multirow[t]{2}{*}{ Altena [24] } & 2009 & M & 15 & $59.0(11.7)$ & 53 & 100 & 100 & 63 & Preferably daily & Slow Music \\
\hline & & C & 15 & $60.0(11.0)$ & 47 & 100 & 100 & & & $\begin{array}{l}\text { Resperate }^{\oplus} \text { (Device Guided } \\
\text { Breathing Exercises) }\end{array}$ \\
\hline \multirow[t]{2}{*}{ Pandic [22] } & 2008 & M & 22 & $66.5(8.3)$ & 18 & 100 & 77 & 112 & $3 \times /$ week & Relaxing Music \\
\hline & & C & 31 & $70.4(8.7)$ & 32 & 100 & 77 & & & $\begin{array}{l}\text { Resperate }{ }^{\circledast} \text { (Device Guided } \\
\text { Breathing Exercises) }\end{array}$ \\
\hline \multirow[t]{2}{*}{ Logtenberg [23] } & 2007 & M & 15 & $59.0(11.7)$ & 67 & 100 & 100 & 56 & $1 \times /$ day & Various Kinds of Music \\
\hline & & C & 15 & $62.7(6.0)$ & 20 & 100 & 100 & & & $\begin{array}{l}\text { Resperate }^{\oplus} \text { (Device Guided } \\
\text { Breathing Exercises) }\end{array}$ \\
\hline \multirow[t]{2}{*}{ Schein [21] } & 2001 & M & 29 & $56.5(8.0)$ & 39 & 100 & 76 & 56 & $1 \times /$ day & $\begin{array}{l}\text { Quiet Synthesized Music } \\
\text { with Non-Identifiable Rhythm }\end{array}$ \\
\hline & & C & 32 & $57.8(9.4)$ & 56 & 100 & 91 & & & $\begin{array}{l}\text { Breathe with Interactive } \\
\text { Music (BIM) Device }\end{array}$ \\
\hline \multirow[t]{2}{*}{ Grossman [26] } & 2001 & M & 15 & $50.0(4.0)$ & 67 & 100 & 53 & 56 & $1 \times /$ day & $\begin{array}{l}\text { Quiet Synthesized Music } \\
\text { with Non-Identifiable Rhythm }\end{array}$ \\
\hline & & $C$ & 18 & $52.0(12.0)$ & 72 & 100 & 56 & & & $\begin{array}{l}\text { Breathe with Interactive } \\
\text { Music (BIM) Device }\end{array}$ \\
\hline
\end{tabular}

$R C T$ randomized controlled trial, $M$ music arm, $C$ control arm, $H T$ hypertension

${ }^{\text {a }}$ Study with Resting period/No intervention as control group

${ }^{\mathrm{b}}$ This study used music therapy whereas the others used recorded music interventions

of music interventions, however this decrease did not reach statistical significance. In the subgroup of three studies with a standard medical therapy or resting control group, random-effects analysis revealed a trend towards a blood pressure decrease in both the intervention and the control groups, while fixed-effect analysis showed a significant decrease in both groups [18-20].

Unfortunately, a valid comparison between the music intervention- and control group did not prove possible, and a cause-effect relationship between music interventions and hypertension remains to be determined.

Research has shown that relatively small decreases, as low as $5 \mathrm{mmHg}$ reduction in systolic blood pressure, would result in $7 \%$ reduction in all-cause mortality, $9 \%$ reduction in coronary heart disease related mortality and
$14 \%$ reduction in stroke-related mortality $[1,27]$. These numbers illustrate the substantial benefit of even small decreases in blood pressure, and if indeed in future studies music interventions prove to be effective, it would provide a valuable low cost therapeutic measure.

The mechanism by which music modulates blood pressure remains unclear. Studies on device-guided breathing hypothesize that reduction in blood pressure is achieved by modulating autonomous cardiovascular regulation by slowing down the breathing frequency [2, 21-25]. As a result, baroreflex sensitivity is lowered, parasympathetic tonus increases and sympathetic tonus decreases, resulting in a decrease in blood pressure. Music listening might elicit the same relaxation response, resulting in a decrease in blood pressure. Another possible 
Table 2 Pooled outcome measures of music intervention arms of included studies

\begin{tabular}{|c|c|c|c|c|c|c|}
\hline First author & $\begin{array}{l}\text { SBP baseline } \\
(\mathrm{mmHg})\end{array}$ & $\begin{array}{l}\text { SBP end } \\
(\mathrm{mmHg})\end{array}$ & $\begin{array}{l}\text { DBP baseline } \\
(\mathrm{mmHg})\end{array}$ & $\begin{array}{l}\text { DBP end } \\
(\mathrm{mmHg})\end{array}$ & $\begin{array}{l}\text { Mean SBP } \\
\text { reduction }(\mathrm{mmHg})\end{array}$ & $\begin{array}{l}\text { Mean DBP } \\
\text { reduction }(\mathrm{mmHg})\end{array}$ \\
\hline Bekiroglu [18] & $128.2(6.7)$ & $115.2(5.3)$ & $77.5^{\mathrm{a}}(-)$ & $70.0^{\mathrm{a}}(-)$ & $13.0^{\mathrm{a}}(-)$ & $7.5^{\mathrm{a}}(-)$ \\
\hline Modesti [2] & $131.0(13.0)$ & $129.7^{\mathrm{a}}(-)$ & $79.0(9.1)$ & $77.6^{\mathrm{a}}(-)$ & $1.3(7.0)$ & $1.4(5.4)$ \\
\hline Zanini [19] & $149.7(6.4)$ & $133.8(13.4)$ & $89.1(9.1)$ & 80.1 (10.6) & $15.9^{\mathrm{a}}(-)$ & $9.0^{\mathrm{a}}(-)$ \\
\hline Chan [20] & $143.8(23.8)$ & $130.1(28.1)$ & $73.1(11.5)$ & $67.7(14.0)$ & $17.3^{\mathrm{a}}(-)$ & $5.4^{\mathrm{a}}(-)$ \\
\hline Tang [25] & $145.0(19.0)$ & $139.0(17.0)$ & $74.0(10.0)$ & $71.0(10.0)$ & $6.0^{\mathrm{a}}(-)$ & $3.0^{\mathrm{a}}(-)$ \\
\hline Altena [24] & $133.9(15.7)$ & $131.0(11.5)$ & $78.4(11.1)$ & $75.0(13.2)$ & $2.9(6.1)$ & $3.4(9.2)$ \\
\hline Pandic [22] & $151.8(15.7)$ & $135.1(10.6)$ & $82.7(9.8)$ & 78.7 (7.7) & $16.0^{\mathrm{a}}(-)$ & $4.1^{a}(-)$ \\
\hline Logtenberg [23] & $150.4(8.2)$ & $138.2(10.3)$ & $87.0(8.3)$ & $81.5(8.3)$ & $12.2(9.4)$ & $5.5(7.5)$ \\
\hline Schein [21] & $154.7(8.5)$ & $143.4^{\mathrm{a}}(-)$ & $93.4(7.1)$ & $87.8^{\mathrm{a}}(-)$ & $11.3(12.8)$ & $5.6(6.2)$ \\
\hline Grossman [26] & $155.0(11.0)$ & $152.1(12.1)$ & $94.0(6.0)$ & $92.5(9.1)$ & $2.9(12.1)$ & $1.5(9.1)$ \\
\hline R-E model & 144.4 & 134.3 & 83.6 & 78.2 & 6.0 & 3.5 \\
\hline$(95 \%$ Cl) & $(136.7-152.1)$ & $(124.0-144.5)$ & (78.2-88.9) & (72.6-83.8) & $(1.5-10.4)$ & $(1.4-5.7)$ \\
\hline \multirow[t]{2}{*}{ Heterogeneity } & $X^{2} P<0.001$ & $X^{2} P<0.001$ & $X^{2} P<0.001$ & $X^{2} P<0.001$ & $X^{2} P<0.001$ & $X^{2} P=0.061$ \\
\hline & $1^{2}=97 \%$ & $1^{2}=97 \%$ & $P^{2}=95 \%$ & $\mathrm{I}^{2}=91 \%$ & $I^{2}=84 \%$ & $I^{2}=56 \%$ \\
\hline
\end{tabular}

Data expressed as "mean (SD)", "mean $(95 \% \mathrm{Cl})$ " or proportions

$R-E$ model random-effects model, $S B P$ systolic blood pressure, $D B P$ diastolic blood pressure

${ }^{\mathrm{a}}$ Excluded from analysis due to unavailable measures of dispersion

Table 3 Pooled outcome measures of the studies with both intervention and control arms

\begin{tabular}{|c|c|c|c|c|c|}
\hline & & SBP baseline $(\mathrm{mmHg})$ & SBP end $(\mathrm{mmHg})$ & DBP baseline $(\mathrm{mmHg})$ & DBP end $(\mathrm{mmHg})$ \\
\hline \multirow[t]{3}{*}{ Intervention } & Bekiroglu [18] & $128.2(6.7)$ & $115.2(5.3)$ & $77.5^{\mathrm{a}}(-)$ & $70.0^{\mathrm{a}}(-)$ \\
\hline & Zanini [19] & $149.7(6.4)$ & $133.8(13.4)$ & $89.1(9.1)$ & $80.1(10.6)$ \\
\hline & Chan [20] & $143.8(23.8)$ & $130.1(28.1)$ & $73.1(11.5)$ & $67.7(14.0)$ \\
\hline \multirow[t]{2}{*}{ Heterogeneity } & & $X^{2} P<0.001$ & $X^{2} P<0.001$ & $X^{2} P<0.001$ & $X^{2} P<0.001$ \\
\hline & & $1^{2}=99 \%$ & $1^{2}=96 \%$ & $1^{2}=96 \%$ & $P^{2}=91 \%$ \\
\hline R-E model & & 140.4 & 126.0 & 81.2 & 74.1 \\
\hline$(95 \% \mathrm{Cl})$ & & $(123.7-157.2)$ & $(111.5-140.5)$ & $(65.5-96.9)$ & $(61.9-86.2)$ \\
\hline F-E model & & 138.2 & 117.5 & 82.9 & 75.6 \\
\hline$(95 \% \mathrm{Cl})$ & & $(136.5-140.0)$ & $(115.7-119.2)$ & (80.0-85.9) & $(72.1-79.0)$ \\
\hline \multirow[t]{3}{*}{ Control } & Bekiroglu [18] & $121.2(5.9)$ & $114.7(6.0)$ & $80.0^{\mathrm{a}}(-)$ & $70.0^{\mathrm{a}}(-)$ \\
\hline & Zanini [19] & $145.4(5.6)$ & $141.0(19.8)$ & $86.9(11.3)$ & $83.9(12.4)$ \\
\hline & Chan [20] & $143.7(22.1)$ & $140.9(26.4)$ & $72.7(12.8)$ & $71.4(13.6)$ \\
\hline \multirow[t]{2}{*}{ Heterogeneity } & & $X^{2} P<0.001$ & $X^{2} P<0.001$ & $X^{2} P<0.001$ & $X^{2} P=0.001$ \\
\hline & & $I^{2}=99 \%$ & $I^{2}=96 \%$ & $1^{2}=94 \%$ & $I^{2}=91 \%$ \\
\hline R-E model & & 136.6 & 131.8 & 79.8 & 77.7 \\
\hline$(95 \% \mathrm{Cl})$ & & $(117.6-155.6)$ & $(110.9-152.7)$ & $(65.9-93.8)$ & $(65.4-89.9)$ \\
\hline F-E model & & 132.5 & 117.3 & 80.4 & 78.0 \\
\hline$(95 \% \mathrm{Cl})$ & & $(130.9-134.0)$ & $(115.2-119.3)$ & (76.9-83.9) & $(74.2-81.7)$ \\
\hline
\end{tabular}

Data expressed as "mean (SD)", "mean $(95 \% \mathrm{Cl})$ " or proportions

$R$-E model random-effects model, F-E model fixed-effect model, SBP systolic blood pressure, $D B P$ diastolic blood pressure

${ }^{a}$ Excluded from analysis due to unavailable measures of dispersion 


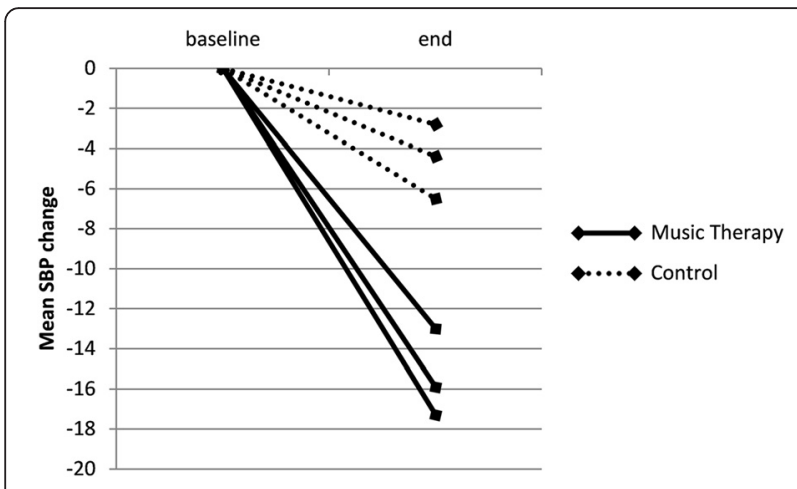

Fig. 2 Mean change in systolic blood pressure in different study-arms in the three comparative studies. SBP = systolic blood pressure

mechanism of action is that music interventions lead to increased brain dopamine levels via a calmodulin-dependent system. This increase in dopamine levels inhibits sympathetic activity via dopamine- 2 receptors which in turn reduces blood pressure [28].

Furthermore, music may direct one's attention to a more pleasant emotional state, thereby triggering feelings associated with physical and mental relaxation [29]. It might also give rise to positive emotions which are connected with the activation of the limbic system, thereby releasing endorphins affecting physiological systems [30]. Moreover, a recent review on magnitude of blood pressure reduction in the placebo arms of hypertension trials found a significant pooled blood pressure reduction of $6 \mathrm{mmHg}$ after placebo intervention [31]. This non-trivial placebo effect should be taken into account when offering these patients any treatment.

The random-effects subgroup analysis of the three trials with comparable control groups showed a trend towards a decrease in blood pressure in both the intervention- and control groups [18-20]. Although a random-effects model may be most appropriate in this case in light of the substantial heterogeneity among these studies, the small number of studies makes quantitative estimation of the

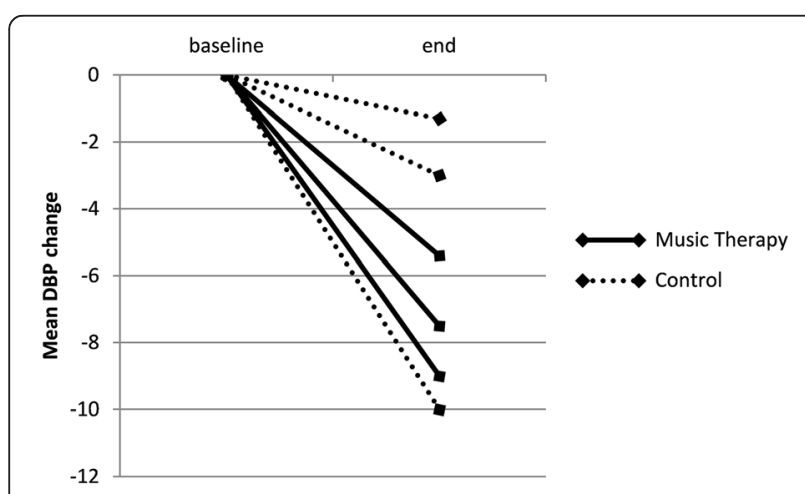

Fig. 3 Mean change in diastolic blood pressure in different study-arms in the three comparative studies. DBP = diastolic blood pressure between-study variance in this subgroup very unreliable. We therefore chose to apply a fixed-effect model to this subgroup as well, which revealed a significant decrease in blood pressure in both intervention- and control groups. However, this fixed-effect analysis does not take the considerable heterogeneity that we observed into account. Thus, in the case of this subgroup, the inherent limitations of both methods renders these analyses inconclusive and the results should be interpreted with caution.

The observed blood pressure decrease in the control groups of this subgroup analysis may be explained in part by the fact that in two of these studies the patients were prescribed a resting period as control, possibly eliciting autonomic responses similar to those described above $[18,20]$. When visually assessing the mean reduction in SBP and DBP in each of these studies, the magnitude of this reduction appeared to be greater in the experimental groups, however a formal comparison of pooled mean reduction of blood pressure between the music and control group was not possible due to missing measures of dispersion concerning this reduction. As a result, a cause-effect relationship could not be established and the only conclusion to be drawn from our meta-analysis, is that we observed a significant decrease in blood pressure in hypertensive patients who underwent music interventions, but also in control patients. These observations could simply be the result of regression toward the mean.

Prevalence of co-morbidities, such as respiratory disease or diabetes mellitus, varied from 26 to $100 \%$ in the three studies that reported it $[18,20,23]$. Data on association of co-morbidities and response to music interventions were not available from these studies. The presence of comorbidities, but also etiology of hypertension, treatment resistance and possible seasonal effects could potentially influence the effect of an intervention $[31,32]$. These aspects should be taken into account when evaluating the effect of the intervention.

\section{Anxiety, depression and quality of life}

Zanini et al. was the only study that found an association between music interventions and quality of life, which might be explained by the use of music therapy in their study in contrast to recorded music interventions in the other studies [19]. Although recorded music interventions were found to be as effective as music therapy in reducing periprocedural pain and anxiety in children undergoing medical procedures [33], it is likely that the effect of music interventions in other settings may indeed be influenced by the method of administration. In some disease states, for instance in psychological or psychiatric disorders or rehabilitation, the involvement of a credentialed music therapy professional may provide better results than listening to music without a music 
therapist. Furthermore, the difference in effectiveness of music therapy compared with recorded music interventions may depend not only on the disease state, but also on which outcome is studied. Improvement of quality of life might be an outcome where dedicated involvement of a therapist providing personalized care may yield greater improvement than solely listening to music. Pain relief on the other hand, may be more strongly regulated by mechanisms triggered by both music therapy and recorded music interventions, such as redirecting someone's attention or activation of the limbic system and the subsequent release of endorphins. Pain relief, in contrast to improvement of quality of life, may therefore be less dependent on involvement of a music therapist. Furthermore, the variation in results concerning quality of life among the included studies might also be explained by the shorter duration of some studies and the difference in study populations.

As for anxiety, Bekiroglu et al. found no significant effects of music interventions [18]. As they suggest, this may be explained by the lack of high anxiety levels at baseline in their patient population, as most likely may be the case in the hypertensive patient population at large. Music interventions might be more effective in decreasing anxiety when patients face a more challenging condition causing extensive anxiety, such as patients suffering from myocardial infarction or facing surgery $[6,10,34,35]$.

\section{Music intervention variability}

A major complicating factor in our analysis of music interventions was the large variation in the type of music administered and the frequency and duration of interventions in the included studies (Table 1). Although the majority of interventions included classical, relaxing or slow music, no clear recommendations exist on how music interventions should be administered in the treatment of high blood pressure. A systematic review on music interventions in anxiety and pain relief in clinical practice provide some insights on which music may be most beneficial [36]. The authors recommend patientpreferred slow and flowing music, approximately 60 to 80 beats per minute, with a minimum duration of $30 \mathrm{~min}$ in length. Research in hypertensive animal models found music containing high-frequency sounds to stimulate dopamine synthesis leading to blood pressure reduction [37]. Moreover, music interventions may be greatly enhanced by preference and familiarity of the patients. Anxiety- and pain reducing effects appear to be greatest when people are given a choice of music to listen to or listen to their own favorite music and other research suggests patient-preferred music, as opposed to prescribed music, to be a critical factor in the effectiveness of music interventions $[5,10,35,38]$. The observed large variation in the types of music used, the applications of music interventions, and the outcomes studied, illustrate the complexity of the topic, and pose a major challenge for future studies.

\section{Limitations}

As with any meta-analysis, the general limitations inherent to meta-analyses should be taken into account [39]. Since the number of patients included in each study is very small and no formal comparison of the treatment effect between the music intervention- and control group was possible, no hard conclusions can be drawn concerning the effect of music interventions on hypertension. As described above, the inherent limitations of both fixed- and random-effects models in the case of a very small, heterogeneous sample of studies rendered our subgroup analysis inconclusive. There was significant heterogeneity in the reported outcomes, which is most likely the result of the large methodological variation among the included studies with regard to patient characteristics, the type of music administered, the duration of each intervention and the follow-up time.

Randomization was mentioned in all trials, though specific information on trial conduct, such as allocation concealment and blinding, was reported poorly and therefore quality assessment of the included studies was limited (see Additional file 2). This, as well as incomplete outcome data, gave rise to a moderate to high risk of bias in the included studies. Publication bias may have affected the outcomes, as some abstracts were unavailable as full-text articles (Fig. 1).

\section{Perspectives}

Our results show that current studies on the effect of music interventions on lowering blood pressure in hypertensive patients do not provide evidence on a possible cause-effect relationship. Since music interventions may be of beneficial value in hypertensive patients, presenting a potential adjuvant to standard pharmacological treatment, there is a need for further high quality research on the subject. Music interventions could not only be of value in case of multidrug therapy or treatment resistant hypertension, but might also be offered as a durable treatment modality in developing countries. However, well-designed high-quality, sufficiently powered randomized controlled trials are first required to establish a cause-effect relationship between music interventions and blood pressure reduction in hypertensive patients.

This research, ideally in the form of large, wellreported randomized controlled trials following the CONSORT statement for nonpharmacological trials with clearly-defined interventions and controls and adequate statistical analyses, could explore the ability of music interventions in lowering blood pressure in a large population, examine the permanence of the reduction in blood 
pressure and elucidate which patients could benefit most [40]. The influence of different forms of music intervention, with regard to factors such as genre and patientpreference, should be investigated. In addition both music therapy and recorded music interventions could be analyzed to obtain more knowledge on the manner of administration of music interventions in the treatment of hypertension. Finally, evaluation of factors that may play a role in the sensitivity to corrections of elevated blood pressure, such as baroreflex sensitivity, can be explored.

\section{Conclusion}

This systematic review and meta-analysis found a trend towards a decrease in blood pressure in hypertensive patients who received music interventions. Unfortunately, this decrease does not provide proof for a cause-effect relationship, as a formal comparison with the control group is lacking. Therefore the most important conclusion of this study is that the quest for answers is still ongoing. Considering the potential value of this safe, low-cost intervention, there is an urgent need for welldesigned, high quality, sufficiently powered randomized studies that assess the efficacy of music interventions in lowering blood pressure.

\section{Availability of data and materials}

The datasets supporting the conclusions of this article are included within the article (and its additional files).

\section{Additional files}

Additional file 1: Literature search. (PDF $64.9 \mathrm{~kb})$

Additional file 2: Risk of bias assessment. (PDF $34 \mathrm{~kb}$ )

Additional file 3: Funnel plots. (PDF 61.9 kb)

\section{Abbreviations}

DBP: diastolic blood pressure; SBP: systolic blood pressure.

\section{Competing interests}

The authors declare that they have no competing interests.

\section{Authors' contributions}

All authors participated in the design of the study. AK and JE reviewed all abstracts and eligible articles, performed statistical analyses and drafted the manuscript. JT assisted with data-analysis and drafting of the manuscript. JR, JJ and $A B$ assisted with drafting the manuscript. All authors read and approved the final manuscript.

\section{Acknowledgements}

We would like to thank Wichor Bramer, biomedical information specialist, for his expertise with the literature search. We would like to thank Nanno Kleefstra for providing measures of dispersion for the outcome measure in his trial.

\section{Funding}

Stichting W.M. de Hoop, Johannes Stichting. Both funding bodies declare no role in the design of the study and collection, analysis, and interpretation of data and in writing the manuscript.

\section{Author details}

Department of Pediatric Surgery, Erasmus University Medical Center, Rotterdam, The Netherlands. 'Department of Cardiothoracic Surgery, Erasmus University Medical Center, P.O. Box 2040, 3000CA Rotterdam, The Netherlands. ${ }^{3}$ Department of Cardiology, Erasmus University Medical Center, Rotterdam, The Netherlands. ${ }^{4}$ Department of Neuroscience, Erasmus University Medical Center, Rotterdam, The Netherlands.

Received: 12 October 2015 Accepted: 13 April 2016

Published online: 19 April 2016

\section{References}

1. Chobanian AV, Bakris GL, Black HR, Cushman WC, Green LA, Izzo Jr JL, Jones DW, Materson BJ, Oparil S, Wright Jr JT, et al. The seventh report of the Joint National Committee on Prevention, Detection, Evaluation, and Treatment of High Blood Pressure: the JNC 7 report. JAMA. 2003;289(19):2560-72.

2. Modesti PA, Ferrari A, Bazzini C, Costanzo G, Simonetti I, Taddei S, Biggeri A, Parati G, Gensini GF, Sirigatti S. Psychological predictors of the antihypertensive effects of music-guided slow breathing. J Hypertens. 2010;28(5):1097-103.

3. Kearney PM, Whelton M, Reynolds K, Muntner P, Whelton PK, He J. Global burden of hypertension: analysis of worldwide data. Lancet. 2005;365(9455): 217-23.

4. Mancia G, Fagard R, Narkiewicz K, Redon J, Zanchetti A, Bohm M, Christiaens T, Cifkova R, De Backer G, Dominiczak A, et al. 2013 ESH/ESC guidelines for the management of arterial hypertension: the Task Force for the Management of Arterial Hypertension of the European Society of Hypertension (ESH) and of the European Society of Cardiology (ESC). Eur Heart J. 2013;34(28):2159-219.

5. Angioli R, De Cicco NC, Plotti F, Cafa EV, Dugo N, Damiani P, Ricciardi R, Linciano F, Terranova C. Use of music to reduce anxiety during office hysteroscopy: prospective randomized trial. J Minim Invasive Gynecol. 2014;21(3):454-9.

6. Han L, Li JP, Sit JW, Chung L, Jiao ZY, Ma WG. Effects of music intervention on physiological stress response and anxiety level of mechanically ventilated patients in China: a randomised controlled trial. J Clin Nurs. 2010; 19(7-8):978-87.

7. Kamioka H, Tsutani K, Yamada M, Park H, Okuizumi H, Tsuruoka K, Honda T, Okada S, Park SJ, Kitayuguchi J, et al. Effectiveness of music therapy: a summary of systematic reviews based on randomized controlled trials of music interventions. Patient Prefer Adherence. 2014;8:727-54.

8. Maratos AS, Gold C, Wang X, Crawford MJ. Music therapy for depression. Cochrane Database Syst Rev. 2008;1:CD004517.

9. Loomba RS, Arora R, Shah PH, Chandrasekar S, Molnar J. Effects of music on systolic blood pressure, diastolic blood pressure, and heart rate: a metaanalysis. Indian Heart J. 2012;64(3):309-13.

10. Bradt J, Dileo C, Potvin N. Music for stress and anxiety reduction in coronary heart disease patients. Cochrane Database Syst Rev. 2013;12:CD006577.

11. American Music Therapy Association. http://www.musictherapy.org/about/ quotes/. Accessed 29 Dec 2015.

12. Grocke DE, Wigram T. Receptive methods in music therapy techniques and clinical applications for music therapy clinicians, educators, and students. London: Jessica Kingsley Publishers; 2007.

13. Bonde LO. Health musicing - music therapy or music and health? A model, empirical examples and personal reflections. Music Arts Action. 2011;3(2):20.

14. Bradt J, Dileo C, Shim M. Music interventions for preoperative anxiety. Cochrane Database Syst Rev. 2013:6:CD006908.

15. Moher D, Liberati A, Tetzlaff J, Altman DG, Group P. Preferred reporting items for systematic reviews and meta-analyses: the PRISMA statement. J Clin Epidemiol. 2009;62(10):1006-12.

16. Borenstein $M$, Hedges LV, Higgins JP, Rothstein HR. A basic introduction to fixed-effect and random-effects models for meta-analysis. Res Synth Methods. 2010;1(2):97-111.

17. Higgins JP, Altman DG, Gotzsche PC, Juni P, Moher D, Oxman AD, Savovic J, Schulz KF, Weeks L, Sterne JA, et al. The Cochrane Collaboration's tool for assessing risk of bias in randomised trials. BMJ. 2011;343:d5928.

18. Bekiroglu T, Ovayolu N, Ergun Y, Ekerbicer HC. Effect of Turkish classical music on blood pressure: a randomized controlled trial in hypertensive elderly patients. Complement Ther Med. 2013;21(3):147-54.

19. Zanini CR, Jardim PC, Salgado CM, Nunes MC, Urzeda FL, Carvalho MV, Pereira DA, Jardim Tde S, Souza WK. Music therapy effects on the quality of life and the blood pressure of hypertensive patients. Arq Bras Cardiol. 2009; 93(5):534-40. 
20. Chan MF, Chan EA, Mok E, Kwan Tse FY. Effect of music on depression levels and physiological responses in community-based older adults. Int J Ment Health Nurs. 2009;18(4):285-94.

21. Schein MH, Gavish B, Herz M, Rosner-Kahana D, Naveh P, Knishkowy B, Zlotnikov E, Ben-Zvi N, Melmed RN. Treating hypertension with a device that slows and regularises breathing: a randomised, double-blind controlled study. J Hum Hypertens. 2001;15(4):271-8.

22. Pandic S, Ekman I, Nord L, Kjellgren Kl. Device-guided breathing exercises in the treatment of hypertension - perceptions and effects. CVD Prev Control. 2008;3(3):163-9.

23. Logtenberg SJ, Kleefstra N, Houweling ST, Groenier KH, Bilo HJ. Effect of device-guided breathing exercises on blood pressure in hypertensive patients with type 2 diabetes mellitus: a randomized controlled trial. J Hypertens. 2007;25(1):241-6.

24. Altena MR, Kleefstra N, Logtenberg SJ, Groenier KH, Houweling ST, Bilo HJ. Effect of device-guided breathing exercises on blood pressure in patients with hypertension: a randomized controlled trial. Blood Press. 2009;18(5):273-9.

25. Tang HY, Harms V, Speck SM, Vezeau T, Jesurum JT. Effects of audio relaxation programs for blood pressure reduction in older adults. Eur J Cardiovasc Nurs. 2009:8(5):329-36.

26. Grossman E, Grossman A, Schein MH, Zimlichman R, Gavish B. Breathingcontrol lowers blood pressure. J Hum Hypertens. 2001;15(4):263-9.

27. Whelton PK, He J, Appel LJ, Cutler JA, Havas S, Kotchen TA, Roccella EJ, Stout R, Vallbona C, Winston MC, et al. Primary prevention of hypertension: clinical and public health advisory from The National High Blood Pressure Education Program. JAMA. 2002;288(15):1882-8.

28. Sutoo D, Akiyama K. Music improves dopaminergic neurotransmission: demonstration based on the effect of music on blood pressure regulation. Brain Res. 2004;1016(2):255-62.

29. Koch ME, Kain ZN, Ayoub C, Rosenbaum SH. The sedative and analgesic sparing effect of music. Anesthesiology. 1998;89(2):300-6.

30. Menon $V$, Levitin DJ. The rewards of music listening: response and physiological connectivity of the mesolimbic system. Neuroimage. 2005; 28(1):175-84.

31. Patel HC, Hayward C, Ozdemir BA, Rosen SD, Krum H, Lyon AR, Francis DP, di Mario C. Magnitude of blood pressure reduction in the placebo arms of modern hypertension trials: implications for trials of renal denervation. Hypertension. 2015;65(2):401-6.

32. Aubiniere-Robb L, Jeemon P, Hastie CE, Patel RK, McCallum L, Morrison D, Walters M, Dawson J, Sloan W, Muir S, et al. Blood pressure response to patterns of weather fluctuations and effect on mortality. Hypertension. 2013; 62(1):190-6

33. Klassen JA, Liang Y, Tjosvold L, Klassen TP, Hartling L. Music for pain and anxiety in children undergoing medical procedures: a systematic review of randomized controlled trials. Ambul Pediatr. 2008:8(2):117-28.

34. Ovayolu N, Ucan O, Pehlivan S, Pehlivan Y, Buyukhatipoglu H, Savas MC, Gulsen MT. Listening to Turkish classical music decreases patients' anxiety, pain, dissatisfaction and the dose of sedative and analgesic drugs during colonoscopy: a prospective randomized controlled trial. World J Gastroenterol. 2006;12(46):7532-6.

35. Hole J, Hirsch M, Ball E, Meads C. Music as an aid for postoperative recovery in adults: a systematic review and meta-analysis. Lancet. 2015;386(10004): 1659-71.

36. Nilsson $U$. The anxiety- and pain-reducing effects of music interventions: a systematic review. AORN J. 2008;87(4):780-807.

37. Akiyama K, Sutoo D. Effect of different frequencies of music on blood pressure regulation in spontaneously hypertensive rats. Neurosci Lett. 2011:487(1):58-60.

38. Jafari H, Emami Zeydi A, Khani S, Esmaeili R, Soleimani A. The effects of listening to preferred music on pain intensity after open heart surgery. Iran J Nurs Midwifery Res. 2012;17(1):1-6.

39. Loannidis JP, Lau J. Pooling research results: benefits and limitations of meta-analysis. Jt Comm J Qual Improv. 1999;25(9):462-9.

40. Boutron I, Moher D, Altman DG, Schulz KF, Ravaud P, Group C. Extending the CONSORT statement to randomized trials of nonpharmacologic treatment: explanation and elaboration. Ann Intern Med. 2008;148(4):295-309.

\section{Submit your next manuscript to BioMed Central and we will help you at every step:}

- We accept pre-submission inquiries

- Our selector tool helps you to find the most relevant journal

- We provide round the clock customer support

- Convenient online submission

- Thorough peer review

- Inclusion in PubMed and all major indexing services

- Maximum visibility for your research

Submit your manuscript at www.biomedcentral.com/submit 